\title{
SCIENTIFIC REPORTS

\section{Inflammatory and antimicrobial properties differ between vaginal Lactobacillus isolates from South African women with non-optimal versus optimal microbiota}

Monalisa T. Manhanzva ${ }^{1}$, Andrea G. Abrahams ${ }^{1}$, Hoyam Gamieldien ${ }^{1}$, Remy Froissart ${ }^{2}$, Heather Jaspan ${ }^{1,3}$, Shameem Z. Jaumdally ${ }^{1}$, Shaun L. Barnabas ${ }^{1}$, Smritee Dabee ${ }^{1}$, Linda G. Bekker ${ }^{1,4}$, Glenda Gray ${ }^{5,6}$, Jo-Ann S. Passmore $\mathbb{C}^{1,7,8}$ \& Lindi Masson ${ }^{1,7,9 *}$

Female genital tract (FGT) inflammation increases HIV infection susceptibility. Non-optimal cervicovaginal microbiota, characterized by depletion of Lactobacillus species and increased bacterial diversity, is associated with increased FGT cytokine production. Lactobacillus species may protect against HIV partly by reducing FGT inflammation. We isolated 80 lactobacilli from South African women with non-optimal (Nugent $4-10 ; n=18$ ) and optimal microbiota (Nugent $0-3 ; n=14$ ). Cytokine production by vaginal epithelial cells in response to lactobacilli in the presence and absence of Gardnerella vaginalis was measured using Luminex. Adhesion to vaginal epithelial cells, $\mathrm{pH}, \mathrm{D} / \mathrm{L}-$ lactate production and lactate dehydrogenase relative abundance were assessed. Lactobacilli from women with non-optimal produced less lactic acid and induced greater inflammatory cytokine production than those from women with optimal microbiota, with IL-6, IL-8, IL-1 $\alpha$, IL-1 $\beta$ and MIP- $1 \alpha / \beta$ production significantly elevated. Overall, lactobacilli suppressed IL-6 (adjusted $p<0.001$ ) and IL-8 (adjusted $p=0.0170$ ) responses to $G$. vaginalis. Cytokine responses to the lactobacilli were inversely associated with lactobacilli adhesion to epithelial cells and D-lactate dehydrogenase relative abundance. Thus, while cervicovaginal lactobacilli reduced the production of the majority of inflammatory cytokines in response to $G$. vaginalis, isolates from women with non-optimal microbiota were more inflammatory and produced less lactic acid than isolates from women with optimal microbiota.

HIV remains a major public health concern, particularly in sub-Saharan Africa where young South African women are at an exceptionally high risk of becoming HIV-infected ${ }^{1,2}$. Increased production of inflammatory cytokines in the female genital tract (FGT) increases HIV acquisition risk, likely by recruiting activated HIV target cells, such as CD4+ T-cells, to the vaginal mucosal epithelium, promoting HIV transcription via nuclear factor kappa B (NF- $\mathrm{KB}$ ) activation, and reducing the integrity of the epithelial barrier ${ }^{3-6}$. Bacterial vaginosis (BV) and non-optimal microbiota including Gardnerella vaginalis, Prevotella bivia, Atopobium spp., Mycoplasma hominis and Mobiluncus spp., are thought to be major drivers of FGT inflammation and HIV risk in sub-Saharan African women ${ }^{7,8}$. BV also increases susceptibility to other sexually transmitted infections (STIs) including Chlamydia trachomatis, Neisseria gonorrhoeae, Trichomonas vaginalis ${ }^{9}$, human papillomavirus ${ }^{10}$, herpes simplex

${ }^{1}$ Institute of Infectious Disease and Molecular Medicine (IDM), University of Cape Town, Cape Town, South Africa. UMR 5290 MIVEGEC, French National Centre for Scientific Research (CNRS), Montpellier, France. 3Seattle Children's Research Institute, University of Washington, Seattle, Washington, USA. ${ }^{4}$ Desmond Tutu HIV Centre, University of Cape Town, Cape Town, South Africa. ${ }^{5}$ Perinatal HIV Research Unit, University of the Witwatersrand, Johannesburg, South Africa. ${ }^{6}$ South African Medical Research Council, Cape Town, South Africa. ${ }^{7}$ Centre for the AIDS Programme of Research in South Africa (CAPRISA), Durban, South Africa. ${ }^{8}$ National Health Laboratory Service, Cape Town, South Africa. ${ }^{9}$ Disease Elimination Program, Life Sciences Discipline, Burnet Institute, Melbourne, Australia. *email: L. Masson@uct.ac.za 


\begin{tabular}{|l|c|l|l|}
\hline Clinical and laboratory findings & $\begin{array}{l}\text { Optimal } \\
\text { microbiota } \\
(\mathbf{N}=14) \mathbf{n}(\%)\end{array}$ & $\begin{array}{l}\text { Non-optimal } \\
\text { Microbiota } \\
(\mathbf{N}=18) \mathbf{n}(\%)\end{array}$ & P-value \\
\hline Black race & $14(100)$ & $18(100)$ & \\
\hline Median age in years (range) & $18.5(16-20)$ & $19(16-22)$ & $\mathrm{p}=0.0001$ \\
\hline Chlamydia trachomatis (PCR positive) & $3(21)$ & $3(17)$ & $\mathrm{p}>0.9999$ \\
\hline Neisseria gonorrhoeae (PCR positive) & $3(21)$ & $0(0)$ & $\mathrm{p}=0.0734$ \\
\hline Trichomonas vaginalis (PCR positive) & $1(7)$ & $0(0)$ & $\mathrm{p}=0.4375$ \\
\hline HSV-2 IgG positive & $0(0)$ & $6(0)$ & $\mathrm{p}=0.0238$ \\
\hline PSA positive & $1(7)$ & $8(44)$ & $\mathrm{p}=0.0443$ \\
\hline Using DMPA & $3(21)$ & $2(11)$ & $\mathrm{p}=0.6313$ \\
\hline Using Nur-Isterate & $10(71)$ & $12(67)$ & $\mathrm{p}>0.9999$ \\
\hline Using Implanon & $1(7)$ & $4(22)$ & $\mathrm{p}=0.3547$ \\
\hline
\end{tabular}

Table 1. Demographic and clinical characteristics of the study population. PCR, polymerase chain reaction; PSA, prostate specific antigen; DMPA, depot medroxyprogesterone acetate. All participants were herpes simplex virus (HSV), Mycoplasma genitalium and Treponema pallidum PCR negative and did not have detectable yeast cells on Gram-stained vaginal smears. Mann-Whitney U test was used to compare continuous data and Fisher's exact test was used for categorical data.

virus type $2(\mathrm{HSV}-2)^{11}$, and adverse reproductive health outcomes ${ }^{12}$. Furthermore, HIV-infected women with $\mathrm{BV}$ are over 3-times more likely to transmit HIV to their partners ${ }^{13,14}$. However, the pathogenesis and immunomodulatory effects of BV are not yet fully understood and current treatment strategies are only partially effective, with inflammatory cytokine concentrations remaining elevated even in women who are successfully treated ${ }^{15,16}$.

On the other hand, optimal vaginal microbiota of healthy pre-menopausal women is dominated by Lactobacillus species, including L. crispatus, L. jensenii, L. gasseri, and L. vaginalis ${ }^{17-19}$. Lactobacillus species appear to play a critical role in regulating inflammatory responses in the FGT and protecting against pathogens, including HIV ${ }^{5,20}$. The role of $L$. iners is however controversial as this species is associated with increased risk of conversion from an optimal to a non-optimal vaginal microbiome $e^{21}$, acquisition of STIs ${ }^{22}$ and upregulation of inflammatory responses ${ }^{23}$. The mechanisms underlying the protective properties of non-iners Lactobacillus species that are considered to be optimal are not fully understood, however it is thought that lactobacilli protect against pathogens by competitively excluding pathogen colonization, and producing antimicrobial compounds such as bacteriocins and lactic acid ${ }^{24}$. Lactic acid exists as L- and D- isomers and it maintains a physiological pH of $<4.5$ in the FGT which inhibits the growth of potential pathogens and may inactivate HIV virus particles ${ }^{25,26}$. Competitive exclusion of pathogens by lactobacilli may modulate inflammation by preventing pathogen interaction with pattern recognition receptors (PRRs) present in the genital epithelium. Lactobacilli and the lactic acid that they produce may also downregulate inflammatory cytokine production by cervicovaginal epithelial cells, which may in turn reduce susceptibility to $\mathrm{HIV}^{27,28}$. A better understanding of the immunomodulatory and other properties of vaginal lactobacilli is critical for the development of biomedical interventions to improve BV treatment and reduce HIV infection risk in women. As few studies have characterized vaginal Lactobacillus isolates in African populations, we evaluated the influence of optimal vaginal Lactobacillus species isolated from South African women. This study included Lactobacillus species that are considered to be optimal and are associated with the lowest levels of inflammatory cytokine production in vivo, in order to further evaluate their immunomodulatory properties that may reduce HIV risk.

\section{Results}

Study population and clinical Lactobacillus isolates. A total of 80 Lactobacillus isolates were obtained from the cervicovaginal secretions of 32 women who participated in the Women's Initiative in Sexual Health (WISH) study in Cape Town, South Africa [L. crispatus $(\mathrm{n}=15)$, L. jensenii $(\mathrm{n}=18)$, L. johnsonii $(\mathrm{n}=5), L$. mucosae $(\mathrm{n}=19)$, L. plantarum $(\mathrm{n}=2)$, L. ruminis $(\mathrm{n}=5)$, L. salivarius $(\mathrm{n}=2)$, L. vaginalis $(\mathrm{n}=14)]$. $\mathrm{BV}$ status was determined by Nugent scoring (women with BV had Nugent scores $\geq 7$; women with intermediate microbiota had Nugent scores between 4-6; women who were BV negative had scores between $0-3)$. We obtained 36 isolates from 18 women with non-optimal microbiota [intermediate microbiota $(\mathrm{n}=5)$ and BV positive $(\mathrm{n}=13)$ ] and 44 isolates from 14 women with optimal microbiota [BV negative $(n=14)$ ] (Table 1). The median age of the women was 18 (range 16-22) years and all of the women were using hormonal contraceptives at the time of sample collection. Six of the women had Chlamydia trachomatis infections, three had Neisseria gonorrhoeae infections, one had a Trichomonas vaginalis infection, one was shedding HSV-2 and only one participant was coinfected with Neisseria gonorrhoeae and Chlamydia trachomatis. At the time of sampling, none of the participants tested positive for Treponema pallidum or had yeast infections determined by examination of Gram stained slides.

Lactobacillus isolates from women with non-optimal induced greater inflammatory cytokine responses in vitro compared to isolates from women with optimal microbiota. To determine whether inflammatory cytokine induction differed between lactobacilli obtained from women with optimal (BV negative; $\mathrm{n}=14)$ and non-optimal (intermediate microbiota and BV positive $(\mathrm{n}=18)$ microbiota, we stimulated vaginal epithelial (VK2) cells with 64 lactobacilli isolates in separate cultures and measured secreted interleukin (IL)-1 $\alpha$, IL-1 $\beta$, IL-6, IL-8, IFN- $\gamma$-inducible protein (IP)-10, macrophage inflammatory protein (MIP)-1 $\alpha$, 
A

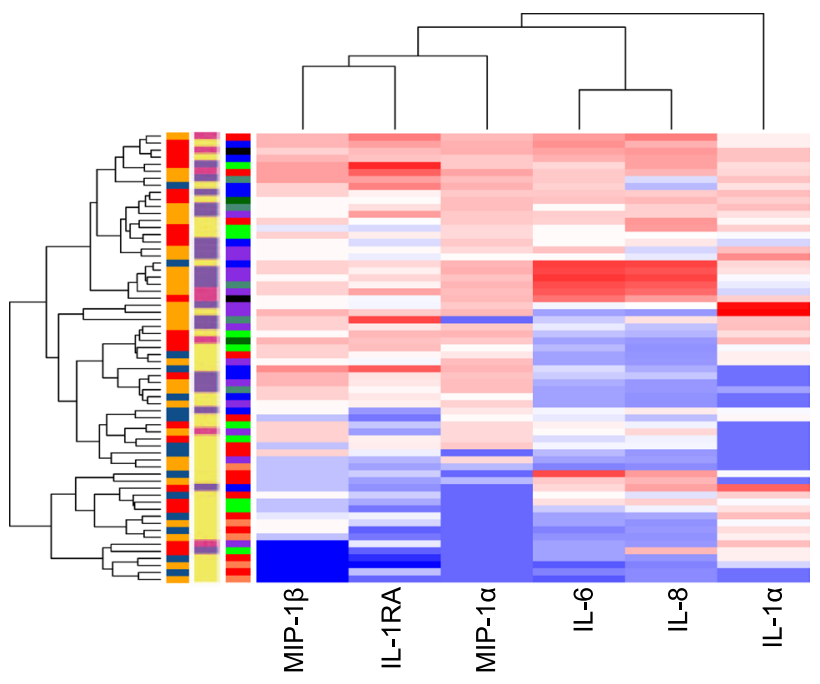

Key

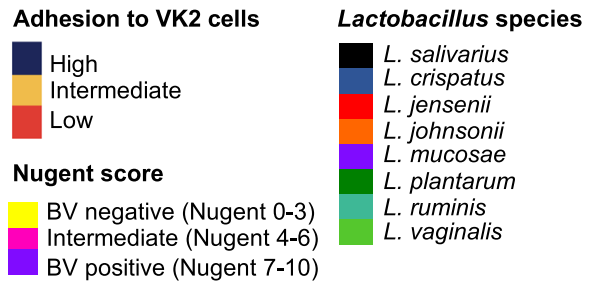

B

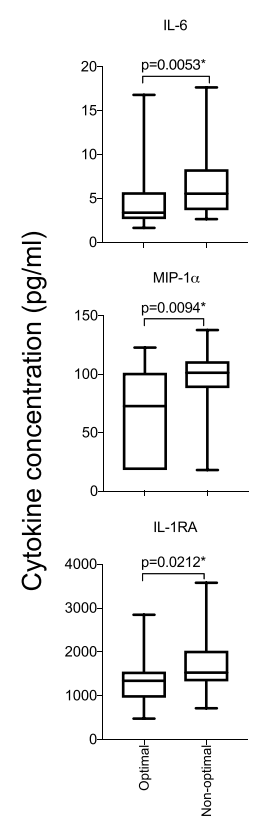

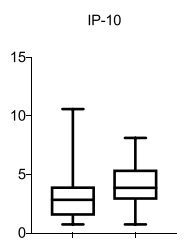

MIP-3 $\alpha$

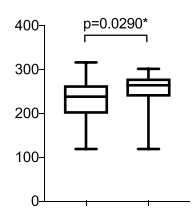

$L-1 \alpha$

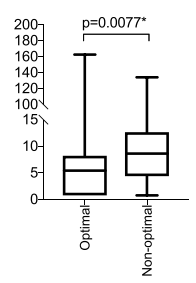

Cytokine concentration

$4.0 \log _{10} \mathrm{pg} / \mathrm{ml}$

$-2.0 \log _{10} \mathrm{pg} / \mathrm{ml}$

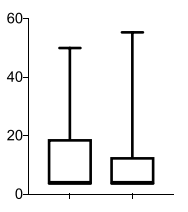

IL-1 $1 \beta$

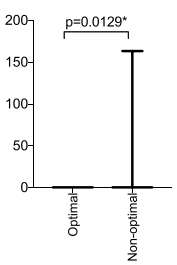

Figure 1. Cytokine production by vaginal epithelial (VK2) cells in response to vaginal Lactobacillus isolates. (A) Heatmap of $\log _{10}$-transformed concentrations of cytokines produced by VK2 cells stimulated with Lactobacillus isolates $(\mathrm{n}=64)$ obtained from women with optimal $(\mathrm{n}=36)$, intermediate $(\mathrm{n}=8)$ and nonoptimal microbiota $(n=20)$. Lactobacillus cultures were adjusted to $4.18 \times 10^{6}$ colony forming units $(\mathrm{CFU}) /$ $\mathrm{ml}$ in antibiotic free keratinocyte serum free media then added to VK2 cell monolayers before being incubated for 24 hours at $37^{\circ} \mathrm{C}$ with $5 \% \mathrm{CO}_{2}$. Cytokine concentrations in the cell culture supernatants were measured using Luminex. Level of adhesion to VK2 cells, bacterial vaginosis (BV) status, and Lactobacillus species are also shown on the left side of the heatmap. (B) Inflammatory cytokine production in response to Lactobacillus isolates from women with optimal microbiota (Nugent $0-3 ; \mathrm{n}=36$ ), including L. crispatus $(\mathrm{n}=6)$; L. jensenii $(\mathrm{n}=12)$, L. johnsonii $(\mathrm{n}=5)$, L. mucosae $(\mathrm{n}=4)$, L. plantarum $(\mathrm{n}=1)$, L. vaginalis $(\mathrm{n}=8)$, compared to women with non-optimal microbiota (Nugent $4-10 ; \mathrm{n}=28)$, including L. crispatus $(\mathrm{n}=5)$, L. jensenii $(\mathrm{n}=2), L$. mucosae $(\mathrm{n}=11)$, L. plantarum $(\mathrm{n}=1)$, L. ruminis $(\mathrm{n}=5)$, L. salivarius $(\mathrm{n}=2)$ and L. vaginalis $(\mathrm{n}=2)$. Data are shown as Tukey box plots. Boxes represent the interquartile ranges, lines within boxes represent medians and whiskers represent minimum and maximum values. P-values were adjusted for multiple comparisons using a false discovery rate step down procedure. *Adjusted p-values $<0.05$ were considered statistically significant.

MIP-1 $\beta$, MIP-3 $\alpha$ and regulatory IL-1 receptor antagonist (RA) concentrations in cell culture supernatants using Luminex. Lactobacilli obtained from women with intermediate microbiota or BV induced greater inflammatory responses than isolates from women with optimal microbiota (Fig. 1A). IL-6 [adjusted (adj.) p =0.020], IL-8 (adj. $\mathrm{p}=0.011)$, IL-1 $\alpha(\operatorname{adj} . \mathrm{p}=0.020)$, MIP-1 $\alpha(\operatorname{adj} . \mathrm{p}=0.020)$, MIP-1 $\beta(\operatorname{adj} . \mathrm{p}=0.040)$ and IL-1RA $(\operatorname{adj} . \mathrm{p}=0.030)$ production in response to isolates from women with non-optimal was significantly greater than lactobacilli from women with optimal microbiota (Fig. 1B). Similar responses were observed when evaluating inflammatory responses induced by isolates from women with intermediate microbiota and BV separately (data not shown). Of the different species evaluated, L. jensenii and L. johnsonii isolates tended to induce lower levels of cytokine production than the other isolates (Figs. $1 \mathrm{~A}$ and 2). However, there were no significant differences in individual cytokines between species after adjusting for multiple comparisons and the level of within-species variation was high (Supplementary Fig. 1).

Logistic regression was used to evaluate the relationship between inflammatory responses to the Lactobacillus isolates and the BV status of the women, adjusting for possible confounders, including the presence of semen which may contain lactobacilli ${ }^{29}$, the use of contraceptives that may influence the microbial populations present $^{30}$ and STIs which are associated with BV status. The relationships between BV status and IL-6 [ $\beta$-coefficient: 2.71; 95\% confidence interval (CI): 0.40-5.01; $\mathrm{p}=0.021$ ], IL-8 ( $\beta$-coefficient: $1.44 ; 95 \%$ CI: $0.34-2.53 ; \mathrm{p}=0.010$ ), MIP-1 $\alpha$ ( $\beta$-coefficient: 1.83; 95\% CI: 0.06-3.60; $\mathrm{p}=0.043)$ and IL-1RA ( $\beta$-coefficient: 4.00; 95\% CI: 0.39-7.62; $\mathrm{p}=0.030)$ remained significant after adjusting for Lactobacillus species, semen contamination [determined 
A

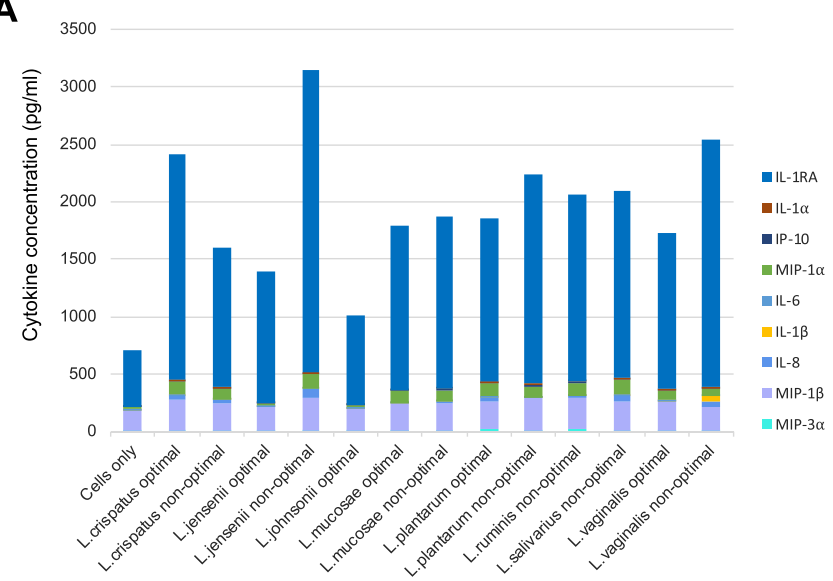

B

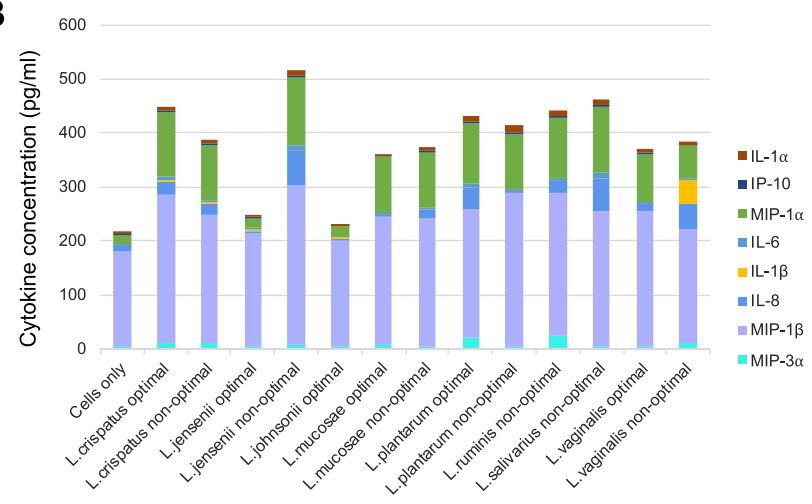

Figure 2. Inflammatory cytokine production by VK2 cells in response to different vaginal Lactobacillus species. Lactobacillus isolates, including L. crispatus $(\mathrm{n}=11)$, . jensenii $(\mathrm{n}=14)$, . johnsonii $(\mathrm{n}=5), L$. mucosae $(\mathrm{n}=15)$, L. plantarum $(\mathrm{n}=2)$, L. ruminis $(\mathrm{n}=5)$, L. salivarius $(\mathrm{n}=2)$ and L. vaginalis $(\mathrm{n}=10)$, were adjusted to $4.18 \times 10^{6}$ colony forming units $(\mathrm{CFU}) / \mathrm{ml}$ in antibiotic free keratinocyte serum free media before being incubated with VK2 cells for 24 hours at $37^{\circ} \mathrm{C}$ with $5 \% \mathrm{CO}_{2}$. Cytokine concentrations were measured in the culture supernatants using Luminex. (A) Stacked bars showing median concentrations of each cytokine interleukin (IL)-1 $\alpha$, IL-1 $\beta$, IL-6, IL-8, IFN- $\gamma$-inducible protein (IP)-10, macrophage inflammatory protein (MIP)-1 $\alpha$, MIP-1 $\beta$, MIP-3 $\alpha$ and regulatory IL-1 receptor antagonist (RA). (B) Stacked bars showing median concentrations of each cytokine excluding IL-1RA (IL-1 $\alpha$, IL-1 $\beta$, IL-6, IL-8, IP-10, MIP-1 $\alpha$, MIP-1 $\beta$ and MIP-3 $\alpha$ ).

by prostate specific antigen (PSA) measurement in the cervicovaginal secretions] and contraceptive use at the time of sample collection. Following adjustment for STI status, MIP- $1 \alpha$ ( $\beta$-coefficient: 1.90; 95\% CI: 0.11-3.70; $\mathrm{p}=0.038$ ) and IL-8 ( $\beta$-coefficient: $1.21 ; 95 \%$ CI: $0.13-2.29 ; \mathrm{p}=0.028)$ production remained significantly associated with the BV status of the women from whom the isolates were obtained.

To further confirm this observation, we compared inflammatory cytokine production in response to 16 different Lactobacillus isolates from women with optimal $(\mathrm{n}=8)$ versus non-optimal $(\mathrm{n}=8)$ microbiota. We again observed a clear difference in inflammatory cytokine production between the groups (Supplementary Fig. 2).

Lactobacillus isolates suppressed vaginal epithelial cell inflammatory responses to $G$. vaginalis. Previous studies have suggested that Lactobacillus species and their metabolites may suppress inflammatory responses to vaginal pathogens and pathobiont $\mathrm{s}^{27,28}$. To investigate this, inflammatory cytokine production by VK2 cells in response to $G$. vaginalis was evaluated. Stimulating the cells with $G$. vaginalis induced production of IL-8 (adj. $\mathrm{p}=0.005)$, IL-6 (adj. $\mathrm{p}=0.005)$, MIP- $1 \alpha$ (adj. $\mathrm{p}=0.014)$, MIP-1 $\beta$ (adj. $\mathrm{p}=0.005)$, MIP-3 $\alpha$ (adj. $\mathrm{p}=0.005)$ and IL-1 $\alpha($ adj. $p=0.005)$. Pretreating the cells with 16 lactobacilli in separate cultures suppressed production of IL-6 (adj. $\mathrm{p}=0.002$ ) and IL-8 (adj. $\mathrm{p}=0.024$ ) in response to $G$. vaginalis, while non-significant decreases in MIP- $1 \alpha$, MIP- $1 \beta$, and MIP-3 $\alpha$ were observed, with the concentrations of these mediators returning to levels that were comparable to Lactobacillus only cultures (Fig. 3A). However, pre-incubation with lactobacilli prior to G. vaginalis stimulation significantly increased the production of IL-1 $\alpha($ adj. $\mathrm{p}=0.010)$ and IL-1 $\beta$ (adj. $\mathrm{p}=0.002$ ) relative to $G$. vaginalis alone or incubation with lactobacilli only. Overall, $L$. jensenii isolates suppressed cytokine responses to G. vaginalis to the greatest degree, followed by L. crispatus, L. vaginalis and L. mucosae (Fig. 3B). The Lactobacillus and G. vaginalis cultures showed no evidence of cytotoxicity to the VK2 cells after bacterial stimulations (Supplementary Fig. 3). 
A
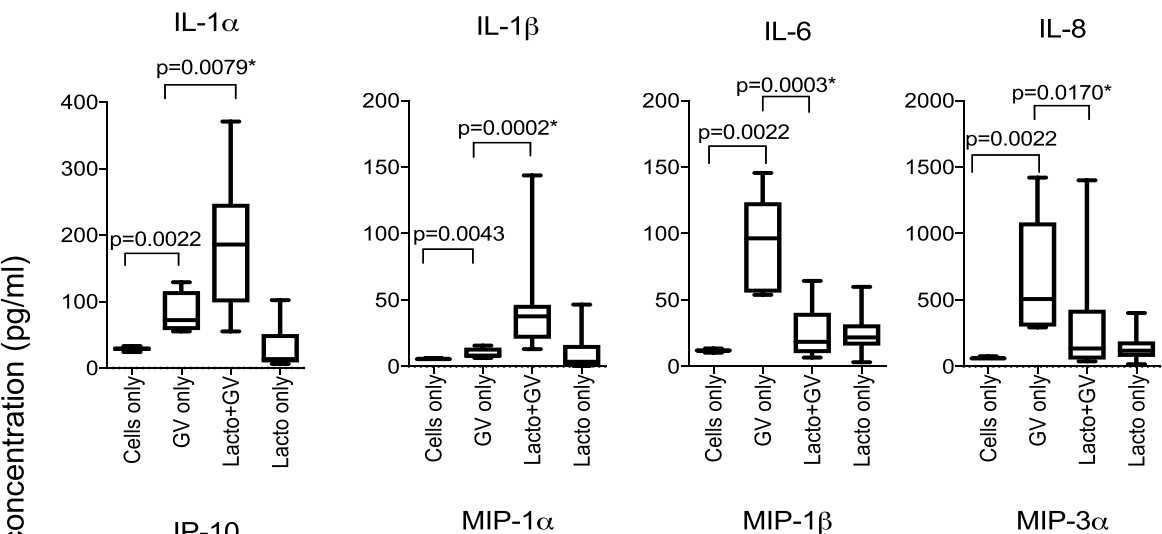

IP-10

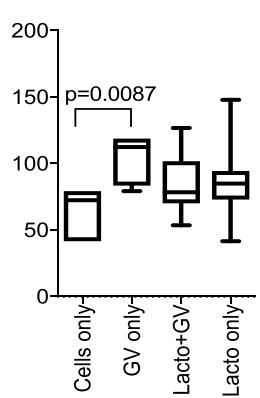

MIP-1 $\beta$

MIP-3 $\alpha$

B
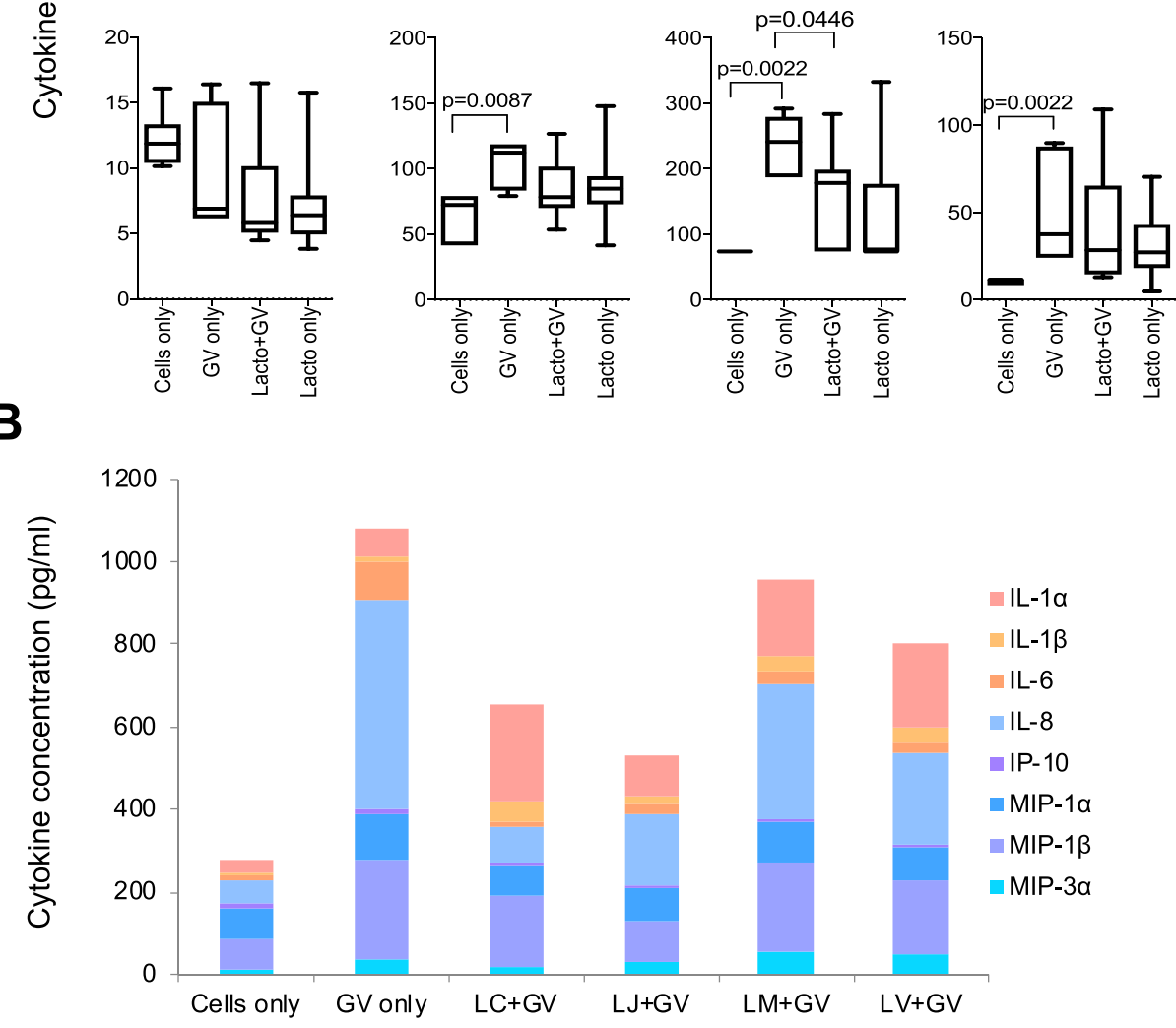

Figure 3. Cytokine production by VK2 cells in response to Gardnerella vaginalis in the presence or absence of clinical Lactobacillus isolates $(\mathrm{n}=16)$. Immortalized VK2 cells were cultured to confluence and then treated with Lactobacillus isolates adjusted to $4.18 \times 10^{6}$ colony forming units (CFU) $/ \mathrm{ml}$ in antibiotic free keratinocyte serum free media before being incubated for 5 hours at $37^{\circ} \mathrm{C}$ with $5 \% \mathrm{CO}_{2}$. G. vaginalis cultures at a concentration of $1 \times 10^{7} \mathrm{CFU} / \mathrm{ml}$ were then added and incubated for a further 20 hours. Cytokine concentrations were measured in the culture supernatants using Luminex. Mann Whitney U tests were used to compare cytokine responses and $\mathrm{p}$-values were adjusted for multiple comparisons using a false discovery rate step down procedure. (A) Data are presented as Tukey box plots. Boxes represent the interquartile ranges, lines within boxes represent medians and whiskers represent minimum and maximum values. *Adjusted p-values $<0.05$ were considered to be statistically significant. (B) Stacked bars showing the median concentrations of all pro-inflammatory cytokines and chemokines produced by VK2 cells in response to $G$. vaginalis in the presence or absence of different clinical Lactobacillus species, including L. crispatus $(\mathrm{n}=4), L$. jensenii $(\mathrm{n}=4)$, L. mucosae $(\mathrm{n}=4)$, and L. vaginalis $(\mathrm{n}=4)$.

Lactobacillus properties differed between women with optimal compared to non-optimal microbiota. We next evaluated factors that could influence the immunoregulatory and protective properties of the lactobacilli by measuring D-lactate and L-lactate production (in bacterial culture and in VK2 cell co-culture), culture $\mathrm{pH}$ levels, lactobacilli growth rates, bacterial sizes and levels of adhesion to VK2 cells. To evaluate lactobacilli adhesion to epithelial cells, we co-cultured lactobacilli $(\mathrm{n}=64)$ with VK2 cells for 2 hours, washed off unbound bacteria and qualitatively evaluated adhesion by Gram stain and microscopy. Lactobacilli 
A
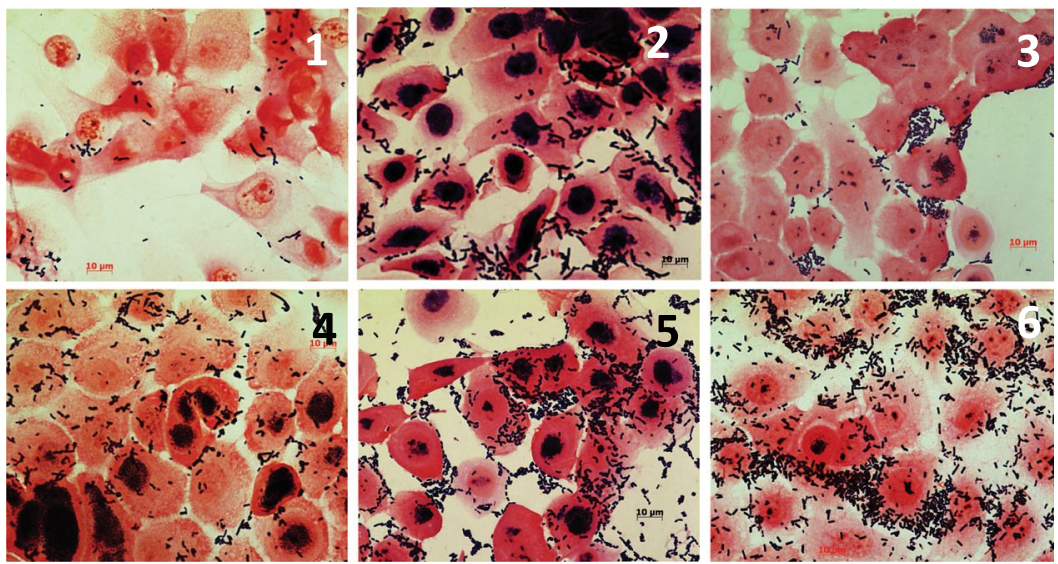

B

\section{C}
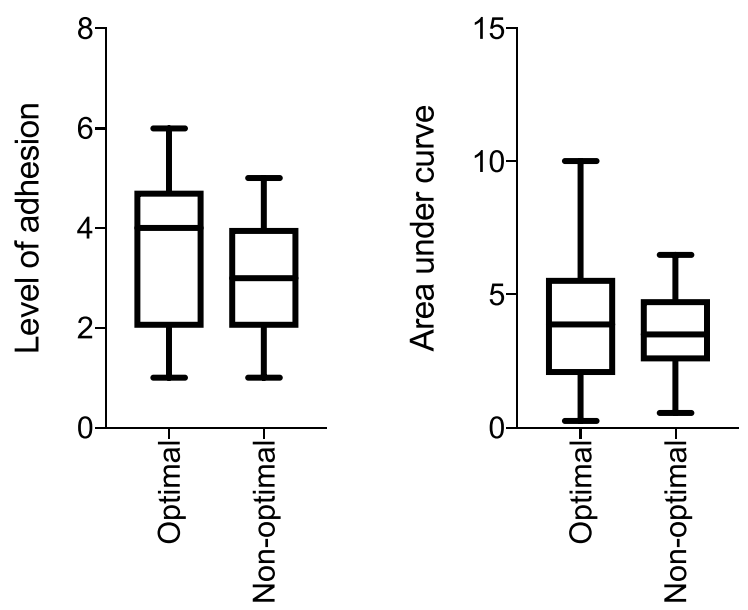

D

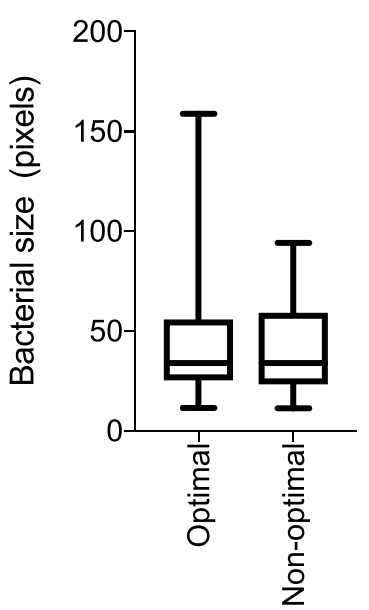

Figure 4. (A) Gram stained images of Lactobacillus adhesion to VK2 cells. Lactobacillus isolates $(\mathrm{n}=64)$ were cultured and adjusted to $4.18 \times 10^{6}$ colony forming units (CFU)/ $\mathrm{ml}$ in antibiotic free keratinocyte serum free media before being added to VK2 cell monolayers in chamber slides and incubated for 2 hours at $37^{\circ} \mathrm{C}$ with $5 \% \mathrm{CO}_{2}$. Non-adherent bacteria were removed with sterile phosphate buffered saline (PBS) before the slides were Gram stained. Representative images of the Gram stained slides were collected and Lactobacillus isolates were ranked according to level of adhesion in ascending order from least adherent (1) to the most adherent (6). Level of adhesion to VK2 cells, growth rates and lengths of Lactobacillus isolates obtained from women with optimal [Nugent score: 0-3 $(\mathrm{n}=36)$ ] and non-optimal microbiota [Nugent score: $4-10(\mathrm{n}=28)$ ]. (B) Adhesion was determined by adding Lactobacillus cultures adjusted to $4.18 \times 10^{6}$ colony forming units (CFU)/ml in antibiotic free keratinocyte serum free media to VK2 cell monolayers and incubating for 2 hours at $37^{\circ} \mathrm{C}$ with $5 \% \mathrm{CO}_{2}$. Non-adherent bacteria were removed with sterile phosphate buffered saline (PBS) before the slides were Gram stained. Each isolate was then scored according to level of adhesion (1-6) by two individuals blinded to the cytokine profiles of the isolates. (C) Growth rates were evaluated by measuring the optical densities at a wavelength of $600 \mathrm{~nm}$, of Lactobacillus cultures initially adjusted to $4.18 \times 10^{6} \mathrm{CFU} / \mathrm{ml}$ and incubated in de Man Rogosa and Sharpe (MRS) broth anaerobically for 24 hours. The areas under the curve were determined during the active phase of growth. (D) Relative bacterial size. Single colonies were picked from Lactobacillus cultures $(n=64)$ and smears were prepared on microscope slides and Gram-stained before taking images at 1,000x magnification. Bacterial length was determined from the images using Image J software. The mean of five measurements for each isolate was used for analysis. Boxes represent the interquartile ranges, lines within boxes represent medians and whiskers represent minimum and maximum values. P-values $<0.05$ were considered statistically significant.

were ranked according to the level of adhesion by scoring each image on a scale of 1 to 6 (Fig. 4A). It was found that lactobacilli adhesion to VK2 cells did not differ significantly between isolates from women with non-optimal versus those from women with optimal microbiota (Fig. 4B). Additionally, no significant differences were noted for Lactobacillus growth rates and sizes (Fig. 4C,D).

Culture $\mathrm{pH}$ was measured using a $\mathrm{pH}$ meter, lactate was measured using ELISA and lactic acid concentrations were calculated using the Henderson-Hasselbach equation ${ }^{31}$. All of the lactobacilli isolates produced D-lactate in both bacterial and cell co-culture, but not all produced L-lactate. Total lactic acid strongly correlated with culture acidification in both cell co-culture $(\mathrm{p}<0.0001$; rho $=-0.7912)$ and in bacterial culture $(\mathrm{p}<0.0001$; 
A

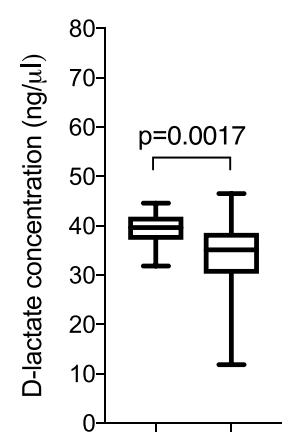

$\mathbf{E}$

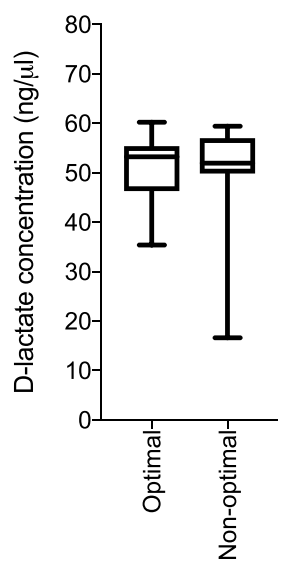

B

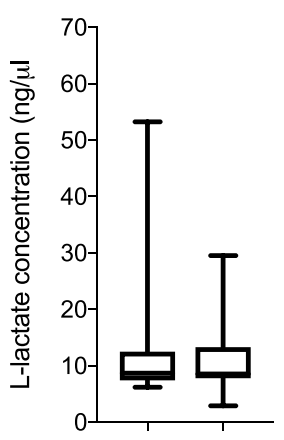

$\mathbf{F}$

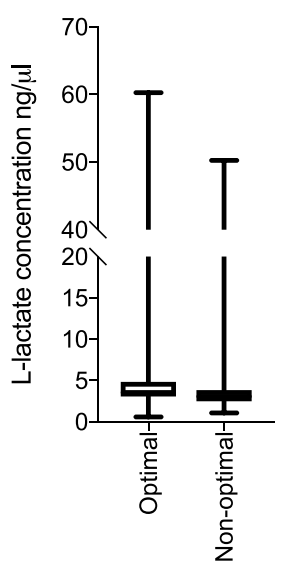

C

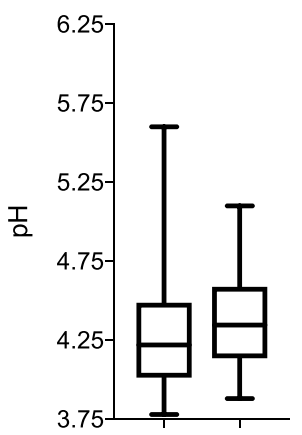

G

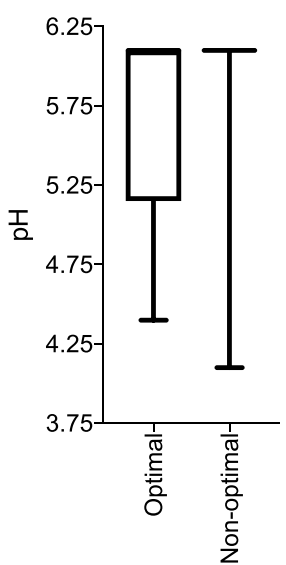

D

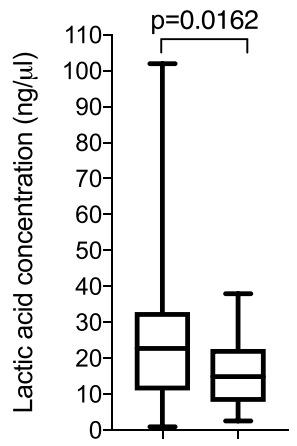

H

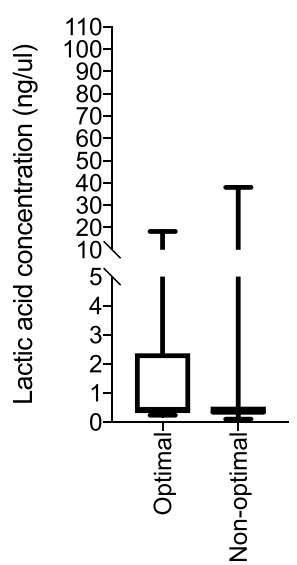

Figure 5. Comparison of D-lactate production, L-lactate production, culture acidification and total lactic acid production by clinical Lactobacillus isolates in bacterial cultures. (A-D) Characteristics in de Man Rogosa and Sharpe (MRS) culture; (E-H) Characteristics in Lactobacillus-VK2 cell co-cultures. Lactobacillus isolates obtained from women with optimal $(n=36)$ and non-optimal microbiota $(n=28)$ were cultured and adjusted to $4.18 \times 10^{6}$ colony forming units $(\mathrm{CFU}) / \mathrm{ml}$ in MRS broth and incubated anaerobically for 24 hours, or adjusted to $4.18 \times 10^{6} \mathrm{CFU} / \mathrm{ml}$ in antibiotic free keratinocyte serum free media before being added to VK2 cell monolayers and incubated for 24 hours at $37^{\circ} \mathrm{C}$ under $5 \% \mathrm{CO}_{2}$. Supernatants were collected and the concentrations of D-lactate, L-lactate were determined using D-Lactate Colorimetric and Lactate Assay kits. Culture $\mathrm{pH}$ was measured using a $\mathrm{pH}$ meter in bacterial cultures and $\mathrm{pH}$ strips in cell co-cultures. Total lactic acid was calculated using the Henderson-Hasselbalch equation. Boxes represent the interquartile ranges, lines within boxes represent medians and whiskers represent minimum and maximum values. P-values $<0.05$ were considered statistically significant.

rho $=-0.9034)$. Isolates from women with non-optimal microbiota produced significantly lower amounts of D-lactate $(\mathrm{p}=0.0017)$ and lactic acid $(\mathrm{p}=0.016)$ in bacterial culture compared to those from women with optimal microbiota (Fig. 5). However, neither D- nor L-lactate production differed significantly between species (Supplementary Fig. 4).

Inflammatory cytokine production was associated with Lactobacillus adhesion to vaginal epithelial cells, D-lactate production and D-lactate dehydrogenase relative abundance. As lactic acid production by lactobacilli, as well as competitive exclusion of pathogens, may influence inflammatory responses, we next evaluated the relationships between inflammatory cytokines and lactate production and adhesion to vaginal epithelial cells. Overall, highly adherent isolates induced lower cytokine responses (Fig. 1A). Lactobacillus adhesion to VK2 cells correlated negatively with IL-6 $(\mathrm{p}=0.0018$, adj. $\mathrm{p}=0.0162$, rho $=-0.3835)$, IL-8 $(\mathrm{p}=0.0242$, adj. $\mathrm{p}=0.0726$, rho $=-0.2815)$, MIP- $1 \alpha(\mathrm{p}=0.0233$, adj. $\mathrm{p}=0.0726$, rho $=-0.2833)$ and IL-1RA ( $\mathrm{p}=0.0355$, adj. $\mathrm{p}=0.080$ rho $=-0.2633)$.

To further investigate the impact of competitive binding of the lactobacilli to the VK2 cells, a variation of the cytokine assay was carried out in which unbound lactobacilli were then washed off with PBS before G. vaginalis was added. We found that washing off unbound lactobacilli reduced the level of inflammatory cytokine suppression (Supplementary Fig. 5), suggesting that the unbound lactobacilli also contribute to the immunoregulatory effect, perhaps through the production of metabolites such as lactic acid. 
While L-lactate, culture $\mathrm{pH}$, average bacterial length and growth rates were not associated with cytokine production, D-lactate production was negatively correlated with IL-6 concentrations in Lactobacillus/G. vaginalis co-cultures (rho $=-0.6269 ; \mathrm{p}=0.0082$; adj. $\mathrm{p}=0.066$ ), although this association was not upheld after adjusting for multiple comparisons. A negative trend towards an association between D-lactate and IL-8 production was also observed in these co-cultures ( $\mathrm{rho}=-0.4971 ; \mathrm{p}=0.0501)$. To further evaluate this relationship, lactate dehydrogenase relative abundance in a subset of 44 isolates was assessed using proteomics. It was found that the production of $\mathrm{D}$-lactate by lactobacilli isolates correlated positively with $\mathrm{D}$-lactate dehydrogenase protein relative abundance (Spearman $\mathrm{rho}=0.3457 ; \mathrm{p}=0.0215$ ), while a trend towards a positive correlation was observed between L-lactate production and L-lactate dehydrogenase relative abundance (Spearman rho $=0.2754$; $\mathrm{p}=0.0700$ ). Additionally, IL-6, IL-8, IP-10 and MIP- $1 \alpha$ production by VK2 cells following incubation with the lactobacilli correlated inversely with isolate D-lactate dehydrogenase relative abundance, but not L-lactate dehydrogenase relative abundance (Supplementary Tables 1 and 2). Together these findings suggest that both D-lactate production and the direct interaction between the lactobacilli and epithelial cells play an important role in regulation of inflammatory responses by the lactobacilli.

\section{Discussion}

Understanding the characteristics of Lactobacillus species and strains that may influence genital tract inflammatory cytokine responses and pathogen colonization is critical for the development of more effective treatment strategies for BV in order to move the field of HIV prevention in young women forward. In this study, we used in vitro systems to measure the concentrations of proinflammatory cytokines secreted by vaginal epithelial cells in response to 80 vaginal Lactobacillus isolates and G. vaginalis, a key BV-associated bacterial species. We found that Lactobacillus isolates from women with non-optimal microbiota (Nugent score: 4-10) were significantly more inflammatory than isolates from women with optimal microbiota (Nugent score: 0-3). It was further found that 16 Lactobacillus isolates were able to significantly suppress inflammatory responses to G. vaginalis. Lactobacillus isolates that induced greater inflammatory responses produced less D-lactate dehydrogenase and D-lactate than those that induced little inflammatory cytokine production in VK2 cells. Additionally, less adherent lactobacilli were more inflammatory than those that strongly adhered to vaginal epithelial cells.

In this study, large variation was observed between the inflammatory properties of vaginal Lactobacillus strains, even those of the same species. This highlights the need to understand not just species level changes, but also strain level variation in microbiome studies. Previous studies have shown that women with non-optimal microbiota have higher levels of genital inflammation compared to women with Lactobacillus-dominant microbiota $^{5,8}$. However, to our knowledge, this study is the first to compare the inflammatory properties of lactobacilli isolated from women with non-optimal to those of women with optimal microbiota. Our findings suggest that the lactobacilli themselves may contribute to the inflammatory profile associated with non-optimal bacteria in the FGT, although, given the low relative abundance of lactobacilli in women with non-optimal microbiota ${ }^{5,8,18}$, this contribution may be minimal.

Although some lactobacilli induced inflammatory responses when cultured with vaginal epithelial cells in isolation, overall the lactobacilli significantly suppressed inflammatory responses to G. vaginalis. In this study, incubation of vaginal epithelial cells with $G$. vaginalis alone caused significant upregulation of multiple inflammatory cytokines (IL-6, IL-8, IL-1 $\alpha$, MIP- $1 \alpha$, MIP-1 $\beta$ and MIP-3 $\alpha$ ), while pre-incubation with lactobacilli resulted in significant downregulation of IL-6 and IL-8 and nonsignificant downregulation of each of the chemokines evaluated. These findings are similar to previous studies showing that G. vaginalis induces inflammatory responses both in vitro and in vivo and lactobacilli have immunoregulatory properties in vitro and are associated with low inflammatory cytokine levels in vivo ${ }^{28,32,33}$. Although the majority of inflammatory cytokines and chemokines were lower following pre-incubation with lactobacilli prior to incubation with G. vaginalis, we found that IL-1 $\alpha$ and IL-1 $\beta$ production was significantly higher compared to G. vaginalis and Lactobacillus only cultures. This suggests that co-culture of vaginal epithelial cells with both lactobacilli and G. vaginalis had an additive effect on the IL-1 pathway and that the production of the other cytokines assessed may be regulated through alternative pathways. The IL-1 pathway is regulated both post-transcriptionally and translationally and involves more complex regulated checkpoints compared to other cytokine system $\mathrm{s}^{34,35}$, which may explain the difference in expression of IL-1 compared to other cytokines observed in this study. Nevertheless, the fact that the majority of cytokines were suppressed by lactobacilli and cumulative median cytokine levels were lower following pre-incubation with lactobacilli compared to G. vaginalis only cultures suggests that lactobacilli may decrease HIV acquisition risk by reducing inflammatory cytokine production in the FGT. The mechanisms by which G. vaginalis induces inflammatory responses are not fully understood, however studies have shown that G. vaginalis produces a toxin, vaginolysin, that is cytolytic to host cells ${ }^{36}$. Damaged tissue releases danger associated molecular patterns which activate pattern recognition receptors to induce a pro-inflammatory response ${ }^{37}$. It has further been reported that vaginolysin treatment of HeLa cells in vitro activates the p38 mitogen activated protein kinase pathway and increases IL-8 production ${ }^{36}$. Recently it has been shown that L. crispatus is able to suppress vaginolysin expression by $G$. vaginalis ${ }^{38}$, providing a possible mechanism for the reduced production of some of the cytokines observed in this study.

In order to evaluate possible underlying mechanisms for the increased inflammatory response to lactobacilli from women with non-optimal microbiota that was observed, we assessed a range of properties of the lactobacilli that may influence inflammatory cytokine induction, including D-lactate, L-lactate and lactic acid production, lactate dehydrogenase relative abundance, culture acidification, growth rates, adhesion to vaginal epithelial cells and Lactobacillus sizes. All isolates produced D-lactate, while only some produced L-lactate, and, similar to inflammatory responses, there was a large amount of variation in these properties between strains, even within species. Additionally, isolates from women with non-optimal microbiota produced significantly lower amounts of D-lactate and lactic acid. A previous study similarly found that, while there were no differences in D-lactic 
acid production between different Lactobacillus species isolated from the FGT, isolates from women with BV produced lower amounts compared to those of women with optimal microbiota ${ }^{39}$. This suggests that the amount of vaginal lactic acid is largely dependent on the particular Lactobacillus species or strains that predominate, as previously suggested ${ }^{40}$. Additionally, as lactic acid contributes to maintaining a pH below 4.5 in the FGT which hinders the growth of BV-associated bacteria and pathogens ${ }^{25,31}$, the lower amounts of lactic acid produced by isolates from women with non-optimal microbiota may reflect their inability to protect against colonization by potentially pathogenic bacteria.

D-lactate and D-lactate dehydrogenase production by Lactobacillus isolates were inversely associated with cytokine production, supporting the results of previous studies demonstrating that lactic acid can have anti-inflammatory effects in vitro ${ }^{27}$. Additionally, adhesion of lactobacilli to vaginal epithelial cells was inversely associated with cytokine responses, suggesting that direct interaction between the isolates and vaginal epithelial cells is important for immunoregulation. Previous studies have suggested that the peptidoglycan cell wall, the proteins present in the cell wall, as well as the cell membrane, may influence the immunomodulatory properties of Lactobacillus species ${ }^{41}$. Thus, differential adhesion capabilities may reflect differences in cell wall and membrane properties. It was found that removing unbound lactobacilli and the culture supernatant prior to addition of $G$. vaginalis reduced the level of suppression of inflammatory responses, although cytokine downregulation was still observed. The reduction in cytokine secretion observed in the Lactobacillus/G.vaginalis co-cultures may thus be due to competitive exclusion of $G$. vaginalis interaction with the vaginal epithelial cells as well as an effect of metabolites being secreted by the lactobacilli. It has been shown previously that lactobacilli were able to reduce G. vaginalis adhesion to the mucosal epithelium by approximately $60 \%{ }^{42}$, and that G. vaginalis was displaced from vaginal cells by lactobacilli ${ }^{43}$. Previous studies have additionally shown that vaginal lactobacilli reduce the expression of toll-like receptor (TLR)-4, which recognizes lipopolysaccharide (LPS) in the cell walls of Gram negative bacteria ${ }^{44-46}$. Although it seems that G. vaginalis does not express LPS, lactobacilli may suppress cytokine responses by reducing the production of other pattern recognition receptors ${ }^{47}$. Additionally, studies using cell lines have found that lactobacilli interfere with the nuclear factor kappa light-chain-enhancer of activated B cells (NF-kB) pathway, reducing inflammatory responses in vitro ${ }^{48}$. Contrary to these findings, other studies have observed increased immune activation via the TLR, NF- $\kappa$ B and p38 MAP kinase signalling pathways by some Lactobacillus strains, suggesting that immunomodulation by lactobacilli and the possible underlying mechanisms are highly strain-specific ${ }^{49,50}$.

Although this study provides valuable information about the inflammatory properties of clinical Lactobacillus species and strains, a limitation is that an in vitro model including a transformed primary cell line was utilized to evaluate the characteristics of Lactobacillus isolates and this environment does not perfectly mimic in vivo conditions. Another limitation is that the study was not powered to examine differences in the inflammatory nature within individual species.

In summary, these data show that non-iners vaginal Lactobacillus isolates induced varying levels of inflammatory cytokine production when cultured with vaginal epithelial cells, while isolates from women with non-optimal microbiota were more inflammatory in vitro than isolates from women with optimal microbiota. However, pre-incubation of vaginal epithelial cells with lactobacilli prior to the addition of G. vaginalis, resulted in decreases in the majority of the cytokines assessed. This study suggests that the properties of the particular Lactobacillus strains present in the FGT (including lactic acid production and inflammatory nature) may influence the ability of non-optimal bacteria to colonize this compartment and shows that the immunomodulatory mechanisms of lactobacilli are multifactorial. The findings of this study are relevant to biotherapeutic development, suggesting that it is critical to obtain Lactobacillus isolates from women with optimal microbiota and to fully characterize the inflammatory properties of potential vaginal probiotics.

\section{Methods}

Study design and sample selection. We carried out a cross-sectional observational study to assess the immunoregulatory properties of lactobacilli isolated from cervicovaginal secretions collected from young women who participated in the Women's Initiative in Sexual Health (WISH) study in Cape Town, South Africa ${ }^{8}$. The parent study cohort comprised 149 women (16-22 years) and the present sub-study included 32 women. Demographic data was collected from the women by questionnaire and vulvovaginal swabs were collected for detection of STIs by nucleic acid amplification tests (HSV-1, HSV-2, Mycoplasma genitalium, Trichomonas vaginalis, Neisseria gonorrhoeae, Chlamydia trachomatis and Treponema pallidum), while candidiasis and BV were assessed by Gram stain, microscopy and Nugent scoring. Women with BV had Nugent scores $\geq 7$; women with intermediate microbiota had Nugent scores between 4-6; women who were BV negative had scores between 0-3. Cervicovaginal secretions were also collected using menstrual cups (Softcup, Evofem Inc, San Diego, CA,) and 115 lactobacilli were isolated from the vaginal fluid and stored in 60\% glycerol. From these, 80 isolates (44 from BV negative women, 28 from BV positive women, and 8 from women with intermediate microbiota) were selected for detailed characterization.

Bacterial isolation. Lactobacilli were isolated from cervicovaginal secretions by culturing in de Man Rogosa and Sharpe (MRS) broth for 48 hours at $37^{\circ} \mathrm{C}$ under anaerobic conditions. The cultures were streaked onto MRS agar plates under the same culture conditions, single colonies were picked and then pre-screened microscopically by Gram staining. Matrix Assisted Laser Desorption Ionization Time of Flight (MALDI-TOF), a technique that measures the unique protein profile of an organism, was conducted at the University of the Western Cape to identify the bacteria to species level. Bacterial growth rates in MRS broth under anaerobic conditions were determined by measuring the optical densities, at a wavelength of $600 \mathrm{~nm}$, of lactobacilli cultures initially adjusted to $4.18 \times 10^{6} \mathrm{CFU} / \mathrm{ml}$ at six time-points for 24 hours. 
Vaginal epithelial cell stimulation and measurement of cytokine concentrations. Vaginal epithelial cells (VK2/E6E7 ATCC CRL-2616), that closely resemble the tissue of origin, were maintained in complete keratinocyte serum free media (KSFM) supplemented with $0.4 \mathrm{mM}$ calcium chloride, $0.05 \mathrm{mg} / \mathrm{ml}$ of bovine pituitary extract, $0.1 \mathrm{ng} / \mathrm{ml}$ human recombinant epithelial growth factor and $50 \mathrm{U} / \mathrm{ml}$ penicillin and $50 \mathrm{U} / \mathrm{ml}$ streptomycin (Sigma-Aldrich, St. Louis, Missouri) as described previously. The VK2 cells were seeded into 24-well tissue culture plates, incubated at $37^{\circ} \mathrm{C}$ in the presence of $5 \%$ carbon dioxide and grown to confluency.

Sixteen lactobacilli comprising $4 L$. crispatus, 4 L. jensenii, 4 L. mucosae and $4 L$. vaginalis were each adjusted to $4.18 \times 10^{6} \mathrm{CFU} / \mathrm{ml}$ in antibiotic-free KSFM and added to VK2-cell monolayers in culture and incubated for 5 hours. G. vaginalis ATCC 14018 cultures standardized to $1 \times 10^{7} \mathrm{CFU} / \mathrm{ml}$ in antibiotic-free KSFM were then added to the cells and plates were incubated for a further 20 hours at $37^{\circ} \mathrm{C}$ in the presence of $5 \%$ carbon diox$\mathrm{ide}^{28}$. Supernatants were collected for cytokine and lactate measurement. IL-6, IL-8, IL-1 $\alpha$, IL-1 $\beta$, IP-10, MIP-3 $\alpha$, MIP- $1 \alpha$ and MIP- $1 \beta$ concentrations were measured using a Magnetic Luminex Screening Assay kit (R\&D, Minneapolis, Minnesota). We used a Bio-Plex Suspension Array Reader to collect data and a 5-parameter logistic regression to calculate cytokine concentrations from the standard curves using BIO-plex manager software (version 4; Bio-Rad Laboratories Inc, Hercules, California). Cytokine concentrations below the detectable limit were assigned the value of half the lowest recorded concentration of that cytokine. To confirm VK2 cell viability following bacterial stimulation, we used the Trypan blue exclusion assay. Viable and dead cells were counted using a light microscope. VK2 cell viability was expressed as a percentage of viable cells in relation to the total number of cells counted.

Thereafter, 64 lactobacilli adjusted to $4.18 \times 10^{6} \mathrm{CFU} / \mathrm{ml}$ in antibiotic-free KSFM were used to stimulate VK2 cells for 24 hours at $37^{\circ} \mathrm{C}$ in the presence of $5 \%$ carbon dioxide. Production of IL-6, IL-8, IL-1 $\alpha$, IL-1 $\beta$, IP-10, MIP-3 $\alpha$, MIP- $1 \alpha$, MIP-1 $\beta$ and IL-1RA were measured as described above. The quality of cytokine data was assessed using Spearman Rank test, with technical replicates correlating strongly for all cytokines assessed $(\mathrm{p}<0.001$ for all; Supplementary Table 3$)$.

D- and L-lactate production by Lactobacillus isolates and $\mathrm{pH}$ changes. $\mathrm{D}$ - and L-lactate concentrations were measured in both Lactobacillus MRS culture and in Lactobacillus-VK2 co-culture supernatants. For the evaluation of lactate production in MRS, lactobacilli were adjusted to $4.18 \times 10^{6} \mathrm{CFU} / \mathrm{ml}$ before being incubated for 24 hours under anaerobic conditions. For lactate measurement in co-cultures, supernatants were collected from Lactobacillus-VK2 co-cultures as described above. The concentrations of D-and L-lactate were determined in duplicate using D-Lactate Colorimetric and Lactate Assay kits (Sigma-Aldrich, St Louis, Missouri) according to the manufacturer's protocol. Optical densities were measured at $450 \mathrm{~nm}$ for D-lactate and $570 \mathrm{~nm}$ for L-lactate and values were converted to $\mathrm{ng} / \mu \mathrm{l}$ against standard curve values, according to manufacturer's instructions. Culture $\mathrm{pH}$ in the Lactobacillus-VK2 co-culture systems was measured using $\mathrm{pH}$ strips (Macherey-Nagel, $\mathrm{GmbH}$ and Co., Duren, Germany) and a $\mathrm{pH}$ meter was used for Lactobacillus culture supernatants.

Lactobacillus adhesion to vaginal epithelial cells. Monolayers of VK2 cells were cultured to confluency in 8-well chamber slides (Thermo Fisher Scientific Inc., Waltham, Massachusetts). Lactobacillus isolates were cultured in MRS broth, adjusted to $4.18 \times 10^{6} \mathrm{CFU} / \mathrm{ml}$ in antibiotic-free KSFM and then added to the cells before being incubated for 2 hours at $37^{\circ} \mathrm{C}$ with $5 \%$ carbon dioxide. The cell culture medium was removed from the wells and each well was washed 3 times with $1 \mathrm{ml}$ PBS. The chambers were removed as per manufacturer's instructions before each slide was heat-fixed. The slides were Gram-stained and representative images were collected (Leica ICC50 HD, Leica Microsystems, Wetzlar, Germany). Each isolate was then scored according to level of adhesion (1-6) by two individuals blinded to the cytokine profiles of the isolates. Gram stained images were also taken from single lactobacilli colonies smeared onto slides from MRS agar plates. Relative bacterial size was measured from images of the Gram-stained slides taken at a 1,000x magnification using Image J software. The mean of five measurements for each isolate was used for analysis.

Measurement of lactate dehydrogenase expression by Lactobacillus isolates using mass spectrometry. To further evaluate the role of lactic acid in modulating the inflammatory properties of the lactobacilli, lactate dehydrogenase relative abundance was evaluated using proteomics analysis of 44 of the isolates $(7 \mathrm{~L}$. crispatus, 13 L. jensenii, 5 L. johnsonii, 9 L. mucosae, 1 L. plantarum, 4 L. ruminis, 2 L. salivarus and 3 L. vaginalis). The Lactobacillus isolates were adjusted to $4.18 \times 10^{6} \mathrm{CFU} / \mathrm{ml}$ in MRS and incubated for 24 hours under anaerobic conditions. Following incubation, the cultures were centrifuged and the pellets washed $3 x$ with PBS. Protein was extracted by resuspending the pellets in $100 \mathrm{mM}$ triethylammonium bicarbonate (TEAB; Sigma T7408) $4 \%$ sodium dodecyl sulfate (SDS; Sigma 71736), sonication and incubation at $95^{\circ} \mathrm{C}$ for $10 \mathrm{~min}$. Nucleic acids were degraded using benzonase nuclease (Sigma E1014) and samples were clarified by centrifugation at $10000 \times \mathrm{g}$ for 10 min. Quantification was performed using the Quanti-Pro BCA assay kit (Sigma QPBCA). HILIC beads (ReSyn Biosciences, HLC010) were washed with $250 \mu \mathrm{l}$ wash buffer (15\% ACN, $100 \mathrm{mM}$ Ammonium acetate (Sigma 14267) $\mathrm{pH}$ 4.5). The beads were then resuspended in loading buffer ( $30 \% \mathrm{ACN}, 200 \mathrm{mM}$ Ammonium acetate $\mathrm{pH}$ 4.5). A total of $50 \mu \mathrm{g}$ of protein from each sample was transferred to a protein LoBind plate (Merck, 0030504.100). Protein was reduced with tris (2-carboxyethyl) phosphine (Sigma 646547) and alkylated with methylmethanethiosulphonate (MMTS; Sigma 208795). HILIC magnetic beads were added at an equal volume to that of the sample and a ratio of 5:1 total protein and incubated on the shaker at $900 \mathrm{rpm}$ for $30 \mathrm{~min}$. After binding, the beads were washed four times with $95 \%$ ACN. Protein was digested by incubation with trypsin for four hours and the supernatant containing peptides was removed and dried down. Liquid chromatography tandem mass spectrometry analysis (LC-MS/MS) was conducted with a Q-Exactive quadrupole-Orbitrap (Thermo Fisher Scientific, USA) coupled with a Dionex UltiMate 3000 nano-HPLC system. Raw files were processed with MaxQuant version 1.5.7.4 against a database including the Lactobacillus genus and common contaminants. 
Statistical analysis. Data was analysed using STATA Version 12 (StataCorp, College Station, Texas), GraphPad Prism version 7 (GraphPad software, San Diego, California) and R Version 1.1.447 (The R Foundation for Statistical Computing, Vienna, Austria). Unsupervised hierarchical clustering was used to evaluate overall cytokine production in response to the isolates. Mann-Whitney $\mathrm{U}$ test was used for unmatched comparisons and a false discovery rate step-down procedure was used to adjust p-values for multiple comparisons. Spearman Rank test was used to test for correlations. Multivariate linear and logistic regression analyses were used to adjust for possible confounders.

Ethics approval and participant consent. Ethical approval to conduct the parent study was obtained from the University of Cape Town (UCT) human research ethics committee (UCT HREC: 267/2013). The current sub-study was approved by the UCT human research ethics committee (UCT HREC: 551/2016) and all experiments were performed in accordance with relevant guidelines and regulations. Women older than 18 years provided written informed consent, while those who were 16-17 years old provided assent and written informed consent was obtained from their parents or legal guardians.

\section{Data availability}

The datasets generated during and/or analysed during the current study are available from the corresponding author on reasonable request.

Received: 9 August 2019; Accepted: 5 March 2020;

Published online: 10 April 2020

\section{References}

1. UNAIDS. Report on the global AIDS epidemic 2010. Urban Research 3 (2010).

2. Harrison, A., Colvin, C. J., Kuo, C., Swartz, A. \& Lurie, M. Sustained high HIV incidence in young women in Southern Africa: Social, behavioral, and structural factors and emerging intervention approaches. Curr. HIV/AIDS Rep. 12, 207-215 (2015).

3. Osborn, L., Kunkel, S. \& Nabel, G. J. Tumor necrosis factor- $\alpha$ and interleukin-1 stimulate the human immunodeficiency virus enhancer by activation of the nuclear factor $\kappa$ B. Proc. Natl. Acad. Sci. 86, 2336-2340 (1989).

4. Masson, L. et al. Genital inflammation and the risk of HIV acquisition in women. Clin. Infect. Dis. 61, 260-269 (2015).

5. Anahtar, M. N. et al. Cervicovaginal bacteria are a major modulator of host inflammatory responses in the female genital tract. Immunity 42, 965-976 (2015).

6. Arnold, K. B. et al. Increased levels of inflammatory cytokines in the female reproductive tract are associated with altered expression of proteases, mucosal barrier proteins, and an influx of HIV-susceptible target cells. Mucosal. Immunol. 9, 194-205 (2016).

7. Masson, L. et al. Inflammatory cytokine biomarkers to identify women with asymptomatic sexually transmitted infections and bacterial vaginosis who are at high risk of HIV infection. Sex. Transm. Infect. 92, 186-193 (2016).

8. Lennard, K. et al. Microbial composition predicts genital tract inflammation and persistent bacterial vaginosis in South African adolescent females. Infect. Immun. 86 (2018).

9. Brotman, R. M. et al. Bacterial vaginosis assessed by Gram stain and diminished colonization resistance to incident gonococcal, chlamydial, and trichomonal genital infection. J. Infect. Dis. 202, 1907-1915 (2010).

10. Gillet, E. et al. Bacterial vaginosis is associated with uterine cervical human papillomavirus infection: A meta-analysis. BMC Infect. Dis. 11 (2011).

11. Cherpes, T. L., Meyn, L. A., Krohn, M. A., Lurie, J. G. \& Hillier, S. L. Association between acquisition of herpes simplex virus type 2 in women and bacterial vaginosis. Clin. Infect. Dis. 37, 319-325 (2003).

12. Ness, R. B. et al. A cluster analysis of bacterial vaginosis-associated microflora and pelvic inflammatory disease. Am. J. Epidemiol. 162, 585-590 (2005).

13. Cu-Uvin, S. et al. Association between bacterial vaginosis and expression of human immunodeficiency virus type 1 RNA in the female genital tract. Clinical infectious diseases 33, 894-896 (2001).

14. Cohen, C. R. et al. Bacterial vaginosis associated with increased risk of female-to-male HIV-1 transmission: a prospective cohort analysis among African couples. PLoS Med. 9, e1001251 (2012).

15. Bradshaw, C. S. et al. High recurrence rates of bacterial vaginosis over the course of 12 months after oral metronidazole therapy and factors associated with recurrence. J. Infect. Dis. 193, 1478-1486 (2006).

16. Joag, V. et al. Ex vivo HIV entry into blood CD4+ T cells does not predict heterosexual HIV acquisition in women. PLoS One 13, $1-12(2018)$.

17. Anukam, K. C., Osazuwa, E. O., Ahonkhai, I. \& Reid, G. 16S rRNA gene sequence and phylogenetic tree of Lactobacillus species from the vagina of healthy Nigerian women. African J. Biotechnol. 4, 1222-1227 (2005).

18. Ravel, J. et al. Vaginal microbiome of reproductive-age women. Proc. Natl. Acad. Sci. 108, 4680-4687 (2011).

19. Antonio, M. A., Hawes, S. E. \& Hillier, S. L. The identification of vaginal Lactobacillus species and the demographic and microbiologic characteristics of women colonized by these species. J. Infect. Dis. 180, 1950-1956 (1999).

20. Gosmann, C. et al. Lactobacillus -deficient cervicovaginal bacterial communities are associated with increased HIV acquisition in young South African women. Immunity 46, 29-37 (2017).

21. Verstraelen, H. et al. Longitudinal analysis of the vaginal microbiota in pregnancy suggests that $L$. crispatus promotes the stability of the normal vaginal microbiota and that L. gasseri and/or L. iners are more conducive to the occurrence of abnormal vaginal microbiota. BMC Microbiol. 9, 116 (2009).

22. Van Houdt, R. et al. Lactobacillus iners-dominated vaginal microbiota is associated with increased susceptibility to Chlamydia trachomatis infection in Dutch women: A case-control study. Sex. Transm. Infect. 94, 117-123 (2018).

23. Doerflinger, S. Y., Throop, A. L. \& Herbst-Kralovetz, M. M. Bacteria in the vaginal microbiome alter the innate immune response and barrier properties of the human vaginal epithelia in a species-specific manner. J. Infect. Dis. 209, 1989-1999 (2014).

24. O’Hanlon, D. E., Moench, T. R. \& Cone, R. A. In vaginal fluid, bacteria associated with bacterial vaginosis can be suppressed with lactic acid but not hydrogen peroxide. BMC Infect. Dis. 11, 200-207 (2011).

25. Aldunate, M. et al. Vaginal concentrations of lactic acid potently inactivate HIV. J. Antimicrob. Chemother. 68, 2015-2025 (2013).

26. Tachedjian, G., Aldunate, M., Bradshaw, C. S. \& Cone, R. A. The role of lactic acid production by probiotic Lactobacillus species in vaginal health. Res. Microbiol. 168, 782-792 (2017).

27. Hearps, A. C. et al. Vaginal lactic acid elicits an anti-inflammatory response from human cervicovaginal epithelial cells and inhibits production of pro-inflammatory mediators associated with HIV acquisition. Mucosal. Immunol. 10, 1480-1490 (2017).

28. Chetwin, E. et al. Antimicrobial and inflammatory properties of South African clinical Lactobacillus isolates and vaginal probiotics. Sci. Rep. 9 (2019). 
29. Weng, S. L. et al. Bacterial communities in semen from men of infertile couples: metagenomic sequencing reveals relationships of seminal microbiota to semen quality. PLoS One 9 , e110152 (2014).

30. Brooks, J. P. et al. Effects of combined oral contraceptives, depot medroxyprogesterone acetate and the levonorgestrel-releasing intrauterine system on the vaginal microbiome. Contraception 95, 405-413 (2017).

31. O'Hanlon, D. E., Moench, T. R. \& Cone, R. A. Vaginal pH and microbicidal lactic acid when lactobacilli dominate the microbiota. PLoS One 8, 1-8 (2013).

32. Rose, W. A. et al. Commensal bacteria modulate innate immune responses of vaginal epithelial cell multilayer cultures. PLoS One 7 (2012).

33. Santos, C. M. A. et al. Anti-inflammatory effect of two Lactobacillus strains during infection with Gardnerella vaginalis and Candida albicans in a hela cell culture model. Microbiol. (United Kingdom) 164, 349-358 (2018).

34. Carta, S., Lavieri, R. \& Rubartelli, A. Different members of the IL-1 family come out in different ways: DAMPs vs. cytokines? Front. Immunol. 4, 1-9 (2013).

35. Mayer-Barber, K. D. \& Yan, B. Clash of the Cytokine Titans: Counter-regulation of interleukin-1 and type i interferon-mediated inflammatory responses. Cell. Mol. Immunol. 14, 22-35 (2017).

36. Gelber, S. E., Aguilar, J. L., Lewis, K. L. T. \& Ratner, A. J. Functional and phylogenetic characterization of vaginolysin, the humanspecific cytolysin from Gardnerella vaginalis. J. Bacteriol. 190, 3896-3903 (2008).

37. Tang, D., Kang, R., Coyne, C. B., Zeh, H. J. \& Lotze, M. T. PAMPs and DAMPs: Signal 0s that spur autophagy and immunity. Immunol. Rev. 249, 158-175 (2012).

38. Castro, J., Martins, A. P., Rodrigues, M. E. \& Cerca, N. Lactobacillus crispatus represses vaginolysin expression by BV associated Gardnerella vaginalis and reduces cell cytotoxicity. Anaerobe. 50, 60-63 (2018).

39. Garg, K. B. et al. Metabolic properties of lactobacilli in women experiencing recurring episodes of bacterial vaginosis with vaginal $\mathrm{pH} \geq$ 5. Eur. J. Clin. Microbiol. 29, 123 (2010).

40. Witkin, S. S. et al. Influence of vaginal bacteria and D - and L -lactic acid isomers on vaginal extracellular matrix metalloproteinase inducer: Implications for protection against upper genital tract infections. 4, 1-7 (2013).

41. Chapot-Chartier, M. P. \& Kulakauskas, S. Cell wall structure and function in lactic acid bacteria. Microb. Cell Fact. 13, S9 (2014).

42. Cribby, S., Taylor, M. \& Reid, G. Vaginal microbiota and the use of probiotics. Interdiscip. Perspect. Infect. Dis. 2008, 1-9 (2008).

43. Boris, S., Suárez, J. E., Vázquez, F. \& Barbés, C. Adherence of human vaginal lactobacilli to vaginal epithelial cells and interaction with uropathogens. Infect. Immun. 66 (1998).

44. Janssens, S. \& Beyaert, R. Role of toll-like receptors in pathogen recognition. Clin. Microbiol. Rev. 16, 637-646 (2003)

45. Zariffard, M. R. et al. Induction of tumor necrosis factor- $\alpha$ secretion and toll-like receptor 2 and 4 mRNA expression by genital mucosal fluids from women with bacterial vaginosis. J. Infect. Dis. 191, 1913-1921 (2005).

46. Tobita, K., Watanabe, I. \& Saito, M. Specific vaginal lactobacilli suppress the inflammation induced by lipopolysaccharide stimulation through downregulation of toll-like receptor expression in human embryonic intestinal epithelial cells. Biosci. Microbiota, Food Heal. 36, 39-44 (2016).

47. Sadhu, K. et al. Gardnerella vaginalis has a gram-positive cell-wall ultrastructure and lacks classical cell-wall lipopolysaccharide. J. Med. Microbiol. 29, 229-35 (1989).

48. Lee, J., Hwang, K., Jun, W., Park, C. \& Lee, M. Anti-inflammatory effect of lactic acid bacteria: inhibition of cyclooxygenase-2 by suppressing nuclear factor-kappaB in Raw264.7 macrophage cells. J. Microbiol. Biotechnol. 18, 1683-1688 (2008).

49. Kim, Y.-G. et al. Probiotic Lactobacillus casei activates innate immunity via NF- $\kappa B$ and p38 MAP kinase signaling pathways. Microbes Infect. 8, 994-1005 (2006).

50. Karlsson, M., Scherbak, N., Reid, G. \& Jass, J. Lactobacillus rhamnosus GR-1 enhances NF-kappaB activation in Escherichia colistimulated urinary bladder cells through TLR4. BMC Microbiol. 12, 1-10 (2012).

\section{Acknowledgements}

This work was supported by the South African National Research Foundation (NRF; PI L. Masson) and the South African Medical Research Council (SAMRC; PI L. Masson). The WISH cohort was supported by the European and Developing Countries Clinical Trials Partnership (EDCTP) Strategic Primer grant (SP.2011.41304.038) and the South African Department of Science and Technology (DST/CON 0260/2012; PI J.S. Passmore). The Poliomyelitis Research Foundation (PRF) of South Africa (15/23; PI J.S. Passmore) funded initial bacterial culture and isolation from the WISH cohort. M.T.M. was supported by the Poliomyelitis Research Foundation (PRF), NRF Innovation and the Letten Foundation. L.M. was supported by the National Research Foundation (NRF) of South Africa and the Carnegie Corporation.

\section{Author contributions}

M.T.M. performed the laboratory experiments, analysed the data and wrote the manuscript; A.G.A. performed some of the experiments and contributed to manuscript preparation; H.G. processed clinical samples, isolated lactobacilli and contributed to manuscript preparation; R.F. performed some of the experiments and contributed to manuscript preparation; H.J. assisted with the management of the WISH cohort and contributed to manuscript preparation; S.Z.J., S.D. and S.L.B. assisted with the management of the WISH cohort, processed clinical samples, and contributed to manuscript preparation; J.S.P. was Principal Investigator of the WISH cohort, collected the clinical data, supervised bacterial isolation and contributed to manuscript preparation; L.G.B. and G.G. managed the clinical sites for the WISH study, collected some of the clinical data and contributed to manuscript preparation; L.M. conceptualized the study, supervised the acquisition of the data, analysed the data, and wrote the manuscript.

\section{Competing interests}

The authors declare no competing interests.

\section{Additional information}

Supplementary information is available for this paper at https://doi.org/10.1038/s41598-020-62184-8.

Correspondence and requests for materials should be addressed to L.M.

Reprints and permissions information is available at www.nature.com/reprints. 
Publisher's note Springer Nature remains neutral with regard to jurisdictional claims in published maps and institutional affiliations.

(c) (i) Open Access This article is licensed under a Creative Commons Attribution 4.0 International License, which permits use, sharing, adaptation, distribution and reproduction in any medium or format, as long as you give appropriate credit to the original author(s) and the source, provide a link to the Creative Commons license, and indicate if changes were made. The images or other third party material in this article are included in the article's Creative Commons license, unless indicated otherwise in a credit line to the material. If material is not included in the article's Creative Commons license and your intended use is not permitted by statutory regulation or exceeds the permitted use, you will need to obtain permission directly from the copyright holder. To view a copy of this license, visit http://creativecommons.org/licenses/by/4.0/.

(c) The Author(s) 2020 